\title{
PERANCANGAN SISTEM INFORMASI PEMINJAMAN KREDIT BERBASIS WEBSITE PADA KOPERASI CIPTA BINA USAHA
}

\author{
Heriyanto ${ }^{1}$, Ika Kurniawati ${ }^{2}$ \\ 1,2 Sistem Infomasi, Universitas Nusa Mandiri, Indonesia \\ Email: ${ }^{1}$ heriyanto.hio@nusamandiri.ac.id, ${ }^{2 *}$ contact.ikakurniawati@gmail.com
}

\begin{abstract}
ABSTRAK
Koperasi merupakan salah satu aspek yang menunjang perekonomian masyarakat terutama masyarakat ekonomi rendah dan menengah. Koperasi yang ada ini perlu dikembangkan agar koperasi tersebut dapat memberikan pelayanan yang baik kepada masyarakat. Koperasi Simpan Pinjam Cipta Bina Usaha adalah salah satu koperasi yang membantu menunjang perekonomian masyarakat dengan menyediakan jasa penyimpanan dan peminjaman uang dengan bunga yang rendah. Sistem informasi pengolahan data yang telah ada dirasakan masih belum efektif dan efisien disebabkan karena sistem yang ada masih bersifat stand alone. Oleh karena itu, dibutuhkan suatu pengembangan sistem informasi peminjaman kredit di Koperasi Cipta Bina Usaha yang berbasis client server dengan tujuan untuk mempercepat dan mempermudah proses peminjaman dan pengolahan data pada Koperasi Cipta Bina Usaha. Dalam pengembangan sistem ini data yang diolah adalah data master yang terdiri dari data anggota dan data administrator serta data transaksi yang terdiri dari data penyimpanan simpanan, pengambilan simpanan, peminjaman dan data pembayaran pinjaman. Hasil dari penelitian dan perancangan ini adalah Sistem Informasi peminjaman kredit di Koperasi Cipta Bina Usaha yang berbasis client server dimana user terdiri dari tiga bagian yaitu ketua koperasi, administrasi dan bagian kasir. Berdasarkan pengujian yang telah dilakukan sistem yang dibangun dapat membantu proses pengolahan data secara efektif dan efisien baik pengolahan data anggota, data simpanan, pinjaman serta pembayaran pinjaman.
\end{abstract}

Kata Kunci: perancangan, sistem informasi, kredit, koperasi, php, mysql

\section{PENDAHULUAN 1.1. Latar Belakang}

Perkembangan teknologi di era modern saat ini mengalami kemajuan yang sangat pesat, dimana setiap orang dapat menemui berbagi teknologi di berbagai bidang di sekitar kehidupan manusia yaitu salah satunya adalah dengan adanya teknologi informasi. Teknologi informasi merupakan suatu alat yang dapat memberikan suatu informasi kepada penggunanya untuk memperoleh data atau informasi yang dapat mendukung ketepatan dalam mengambil keputusan dengan menggunakan teknologi yang tepat guna. Teknologi informasi saat ini memiliki pengaruh yang sangat luar biasa bagi semua bidang seperti di bidang usaha, dan selama ini yang sering kita jumpai adalah sistem kredit mikro dalam perbankan yang telah menyalurkan dananya untuk usaha kecil menengah (UKM) (Lasminiasih, dkk : 2016). Sistem kredit dalam skala usaha kecil dan menengah salah satunya adalah koperasi.

Koperasi Cipta Bina Usaha yang bergerak dalam bidang jasa peminjaman uang, setiap hari banyak nya nasabah yang datang untuk melakukan proses peminjaman. Namun karena tidak adanya sistem yang membantu, proses peminjaman yang panjang dan pencatatan data nasabah pun masih dilakukan dengan manual yaitu dicatat dengan buku besar, sehingga menimbulkan banyak masalah, seperti laporan bulanan yang kurang rapi, kesalahan perhitungan, data yang kurang update dan masih banyak lagi masalah yang dijumpai oleh penulis saat melakukan observasi pada Koperasi Cipta Bina
Usaha yang berakaitan dengan aktifitas peminjaman dan pembayaran.

Pemograman berorientasi objek merupakan kombinasi dari teknologi informasi dan aktivitas orang yang menggunakan teknologi itu untuk mendukung operasi dan manajemen perusahaan. Dalam arti yang sangat luas, istilah pemograman berbasis objek yang sering digunakan merujuk kepada interaksi antara orang, proses algoritmik, data, dan teknologi. Perkembangan Teknologi Informasi (TI) yang semakin pesat adalah internet. Hampir setiap orang saat ini telah mengenal internet dan menggunakan internet setiap orang dapat mengakses program yang diinginkan.

Penelitian yang diusulkan yaitu perancangan sistem informasi peminjaman menggunakan bahasa pemrograman PHP dan Mysql sebagai databasenya. Sebuah sistem yang mampu membantu proses peminjaman, mampu memberikan informasi perhitungan pinjaman, mampu mencatat data nasabah dan data pembayaran angsuran dan dapat mencetak laporan bulanan data transaksi kepada pemilik koperasi.

\subsection{Tinjuan Pustaka}

\section{1) Konsep Dasar Sistem Informasi}

Sistem Informasi adalah kumpulan elemen yang saling berhubungan satu sama lain untuk membentuk suatu kesatuan untuk mengintegrasi data, 
memproses dan menyimpan serta mendistribusikan informasi tersebut. (Sutejo, 2006:36).

Pengembangan software waterfall model pertama kali diperkenalkan oleh Winston Royce tahun 1970. Waterfall model merupakan model klasik yang sederhana dengan aliran sistem yang linier. Output dari setiap tahap merupakan input bagi tahap berikutnya. Model ini telah diperoleh dari proses rekayasa lainnya dan menawarkan cara pembuatan rekayasa perangkat lunak secara lebih nyata. Model ini melibatkan tim SQA (Software Quantity Assurance) dengan 5 tahapan, dimana setiap tahapan selalu dilakukan verifikasi atau testing.

\section{2) Konsep Dasar Pemograman}

Pemrograman berorientasi objek atau objectoriented programming (OOP) merupakan suatu pendekatan pemrograman yang menggunakan object dan class. Saat ini konsep OOP sudah semakin berkembang. Hampir setiap perguruan tinggi di dunia mengajarkan konsep OOP ini pada mahasiswanya. Pemrograman yang banyak dipakai dalam penerapan konsep OOP adalah Java dan C++. OOP bukanlah sekedar cara penulisan sintaks program yang berbeda, namun lebih dari itu, OOP merupakan cara pandang dalam menganalisa sistem dan permasalahan pemrograman. Dalam OOP, setiap bagian dari program adalah object. Sebuah object mewakili suatu bagian program yang akan diselesaikan. Beberapa konsep OOP dasar, antara lain :

a) Encapsulation (Class dan Object)

b) Inheritance (Penurunan sifat),

c) Polymorphisme

\section{3) Koperasi}

Suatu perkumpulan beranggotakan orang-orang atau badan hukum, yang memberikan kebebasan kepada anggota untuk masuk dan keluar, dengan bekerja sama secara kekeluargaan menjalankan usaha untuk mempertinggi kesejahteraan jasmaniah para anggotanya. (Harsono, 2006:15). Sebagai salah satu pelaku ekonomi, koperasi merupakan organisasi ekonomi yang berusaha menggerakkan potensi sumber daya ekonomi demi memajukan kesejahteraan anggota. Karena sumber daya ekonomi tersebut terbatas, dan dalam mengembangkan koperasi harus mengutamakan kepentingan anggota, maka koperasi harus mampu bekerja seefisien mungkin dan mengikuti prinsipprinsip koperasi dan kaidah-kaidah ekonomi.

\section{4) Hypertext Preprocessor (PHP)}

Menurut Madcoms, (2013) PHP adalah sebuah bahasa scripting yang terpasang pada HTML. Scriptscript PHP harus tersimpan dalam sebuah server dan dieksekusi atau diproses dalam server tersebut.

dokumen HTML, yang selanjutnya akan ditampilkan kembali ke web browser, karena pemrosesan program PHP dilakukan dilingkungan web server, PHP dikatakan sebagai bahasa sisi server (serverside). Oleh sebab itu, seperti yang telah dijelaskan sebelumnya, kode PHP tidak akan terlihat pada saat user memilih perintah "view Source" pada web browser yang digunakan.

\section{5) Structured Query Language (MySql)}

Berdasarkan pemaparan Kadir. (2014) Structured Query Language (SQL) adalah bahasa yang digunakan untuk mengakses basis data yang tergolong relasional. SQL tidak terbatas hanya untuk mengambil data (query), tetapi juga dapat dipakai untuk menciptakan tabel (CREATE), menghapus tabel (DELETE), menambahkan data ke tabel (INSERT), menghapus data di tabel (DROP), mengganti data di tabel (UPDATE), dan berbagai operasi yang lain.

\section{6) Penelitian Terkait}

Penelitian terkait pengembangan sistem peminjaman kredit telah dilakukan beberapa peneliti. Mulyono (Mulyono, 2013:1-7) merancang suatu sistem informasi pada Koperasi "Sari Mulyo" secara komputerisasi karena pengolahan data pada Koperasi tersebut masih secara konvensional, maka dibuatkan perancangan sistem informasi berbasis website yang nantinya diharapkan dapat mengatasi masalah pengolahan data anggota dan laporan keuangan bagi Koperasi memperbaiki sistem yang ada, agar menyajikan data yang akurat dan tepat waktu.

Penelitian yang dilakukan oleh (Sugeng Santoso, dkk, 2018) yakni membangun Aplikasi Sistem Informasi Pengajuan Kredit Berbasis Web Pada PD. BPR Kerta Raharja Cabang Balaraja, penulis menggunakan metode analisis PIECES untuk menganalisa sistem yang dibutuhkan. Sistem yang dibangun menggunakan bahasa pemrograman PHP dan MySQL untuk membuat database, dreamweaver untuk desain dan UML (Unified Modelling Language) untuk model sistem. Dengan adanya sistem ini dapat mempercepat proses pengajuan kredit serta menjadi lebih akurat dalam informasi yang diperoleh.

(Indra Griha Tofik Isa, D : 2017) melakukan penelitian dengan judul Perancangan Aplikasi Koperasi Simpan Pinjam Berbasis Web (Studi Kasus Koperasi Mitra Setia). Pada penelitian ini bahwa perangkat lunak yang dilakukan pada penelitian ini akan menggunakan metode berorientasi objek, adapun tahapannya Analisis sistem dilakukan dengan metode Object Oriented Analysis (OOA) atau analisis berorientasi objek. Sistem ini akan 
dirancang dengan menggunakan metode Object Oriented Design (OOD) atau perancangan berorientasi objek dengan menggambarkan rancangan sistem menggunakan diagram UML (Unified Modelling Language) yang terdiri dari Use Case Diagram, Aktivity Diagram, Squence Diagram dan Class Diagram Masing-masing aktor akan tergambarkan dengan jelas pada diagram di atas memiliki tugas dan fungsi yang berbeda.

\subsection{Metodologi Penelitian}

\subsubsection{Pengumpulan Data}

Pengumpulan data dapat dilakukan dengan teknik wawancara, teknik observasi, dan teknik kuisioner (Rosa, 2013). Pada penelitian ini kami menggunakan beberapa teknik diantaranya sebagai berikut :

1) Observasi

Penulis melakukan pengumpulan data secara langsung dengan melihat objek penelitian dan melakukan pengamatan langsung di Koperasi Cipta Bina Usaha.

2) Wawancara

Wawancara adalah metode yang digunakan penulis untuk memenuhi skripsi dengan cara tanya jawab pada Bapak Famatoronia Waruwu selaku pemilik Koperasi Cipta Bina Usaha.

3) Studi Pustaka

Dengan metode pengumpulan data dalam studi pustaka ini, penulis mendapatkan sumber data dari beberapa Koperasi dan jurnal yang berkaitan dengan perancangan sistem informasi peminjaman.

\subsubsection{Metode Pengembangan sistem}

Adapun metode yang digunakan dalam pengembangan sistem adalah metode waterfall. Metode waterfall adalah metode dalam mengembangkan sistem yang tahapannya mengalir ke bawah seperti air terjun (C. Tristianto, 2018). Model waterfall terdiri dari lima tahap yang harus diselesaikan satu demi satu dan dapat pindah ke tahap berikutnya apabila tahap sebelumnya sudah selesai (Y. Bassil, 2015). Metode waterfall memiliki tahapan sebagai berikut:

1) Analisa Kebutuhan Website

Penulis menganalisa kebutuhan Website dalam masalah Peminjaman mulai dari data karyawan atau internal Koperasi, data peminjaman atau nasabah Koperasi yang terlibat dalam transaksi peminjaman uang dan peminjaman.

2) Desain

Pada tahapan desain penulis menggunakan UML (Unifield Modeling Languange) sebagai Website architecture system serta ERD (Entity Relationship Diagram) untuk menggambarkan hubungan antar data dalam basis data.
3) Implementation

Pada tahapan ini penulis akan merealisasikan tahapan desain menjadi kode program dengan bahasa PHP yang merupakan salah satu program berorientasi object (OOP).

4) Testing

Penulis menggunakan blackbox testing, yaitu tahapan dimana pengetesan terhadap input dimulai dari pemasukan data nasabah sampai dengan pembuatan laporan detail pinjaman dan angsuran nasabah per bulan.

5) Maintenance

tahapan ini adalah proses modifikasi perangkat lunak, setelah proses testing untuk menyempurnakan keluaran, error, dan peningkatan kualitas dan kinerja perangkat lunak. Adapun tahapan metode waterfall digambarkan seperti pada Gambar 1.

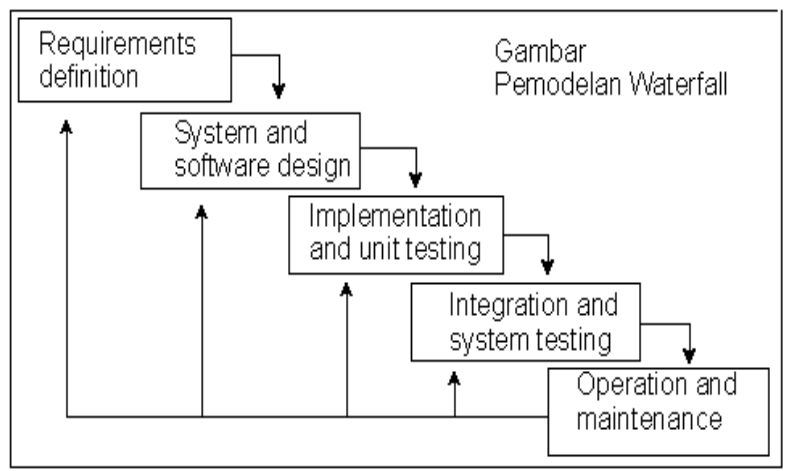

Gambar 1

Pemodelan Waterfall

\section{PEMBAHASAN}

\subsection{Tahap Analisis}

Analisa kebutuhan merupakan langkah awal yang dilakukan agar didapat gambaran dari sebuah sistem yang akan dibuat, sebelum dimulai pengimplementasian pada kode program. Penelitian ini menggunakan Unified Modeling Language (UML) pada perancangan sistem dan perangkat lunak. UML merupakan sekumpulan diagram yang telah memiliki standar untuk menggambarkan rancangan perangkat lunak berorientasi objek (Widodo, 2011). Berikut adalah rancangan Use case diagram pada Koperasi Cipta Bina Usaha, yang merupakan penggambaran dengan melihat secara keseluruhan fungsi-fungsi yang ada pada sistem, terdapat dua aktor yaitu admin dan anggota. 


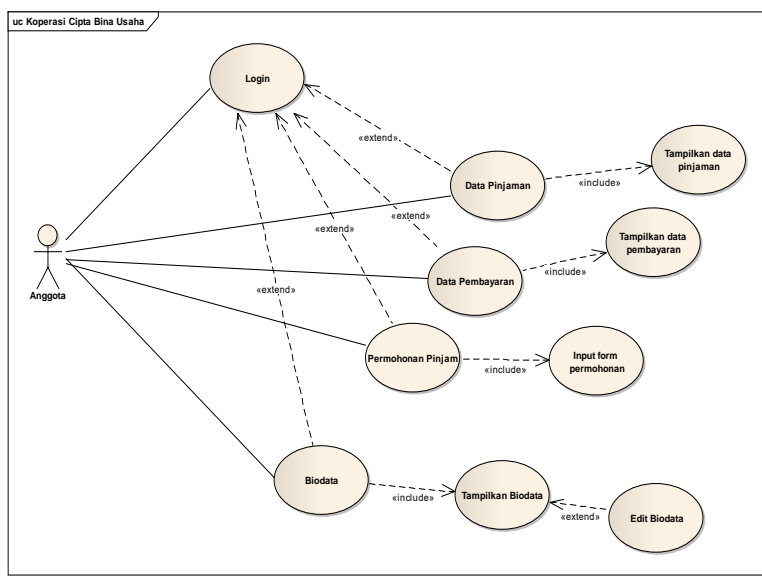

Gambar 2.

Use Case Diagram Halaman Anggota

Peran Anggota dapat melakukan melihat data pinjaman , data angsuran dan biodata diri. Semua fungsi sistem membutuhkan autentifikasi berupa login sistem

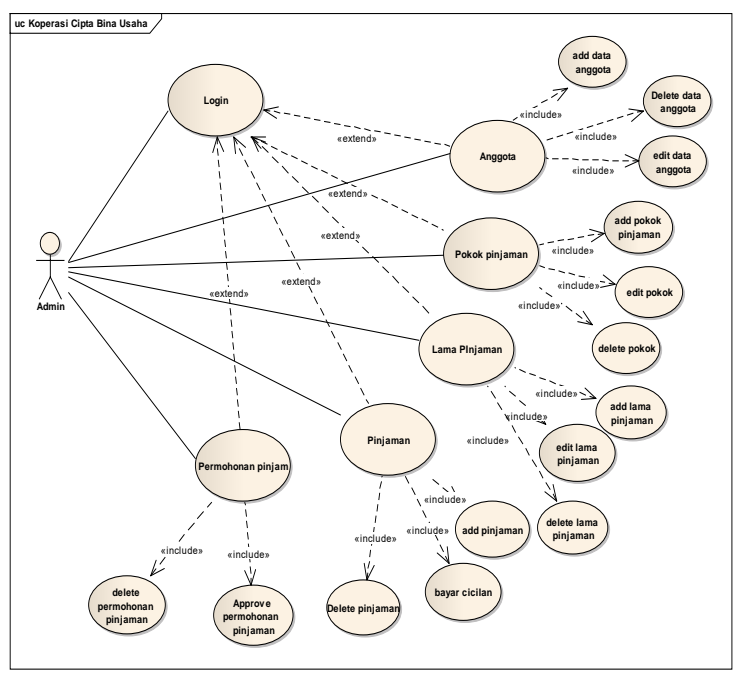

Gambar 3.

Use Case Diagram Halaman Admin

Peran admin diantaranya adalah mengelola data anggota, mengelola data pokok pinjaman, mengelola data lama pinjaman, mengelola data pinjaman. Semua fungsi sistem membutuhkan autentifikasi berupa login sistem.

\subsection{Desain Sistem}

Tahap desain yang akan menggambarkan design database, desain software architecthure dan disain interface dari sistem yang akan dibuat. Di dalam database terdapat beberapa tabel yang saling berelasi (berhubungan) maka dari itu penulis mencoba menggambarkanya menggunakan Logical record Structure . Penggambaran database pada Koperasi Cipta Bina sebagai berikut:

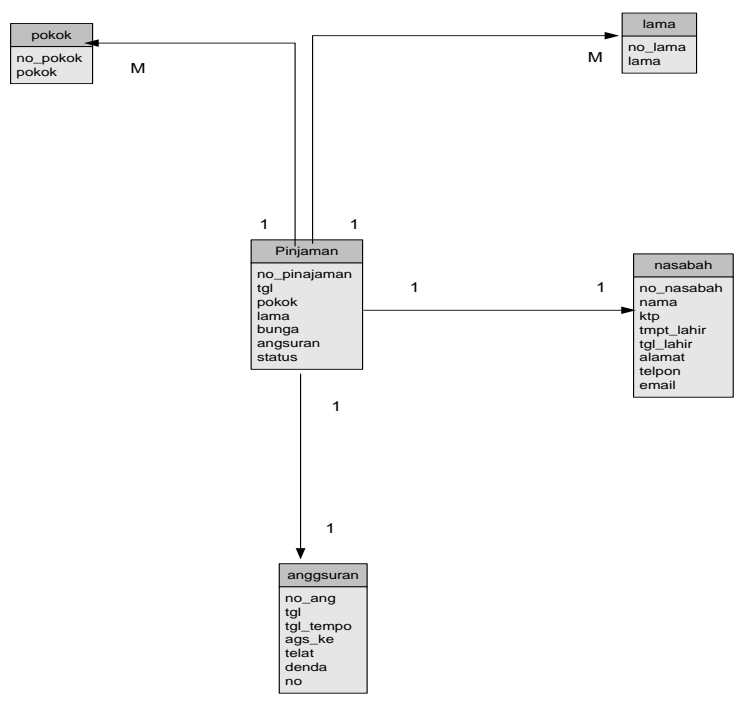

Gambar 4.

Logical Record Structure Koperasi Cipta Bina Usaha

\section{IMPLEMENTASI PROGRAM}

Sistem informasi peminjaman diawali dengan halaman dashboard. Sistem meminta email dan password untuk berinteraksi dengan sistem, baik admin maupun anggota. Berikut detail tampilantampilan tiap halaman website Sistem peminjaman Koperasi Cipta Bina Usaha:

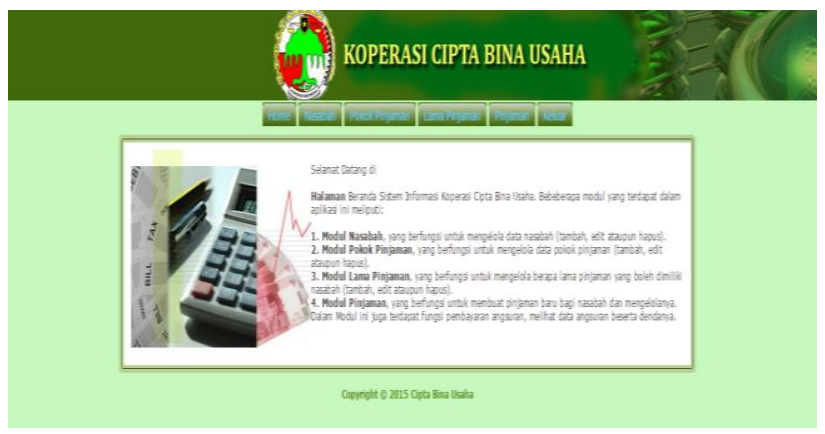

Gambar 5.

Tampilan Halaman Home Admin

Tampilan data nasabah pada gambar 6, administrator dapat melihat,mengedit, dan menghapus data nasabah. 


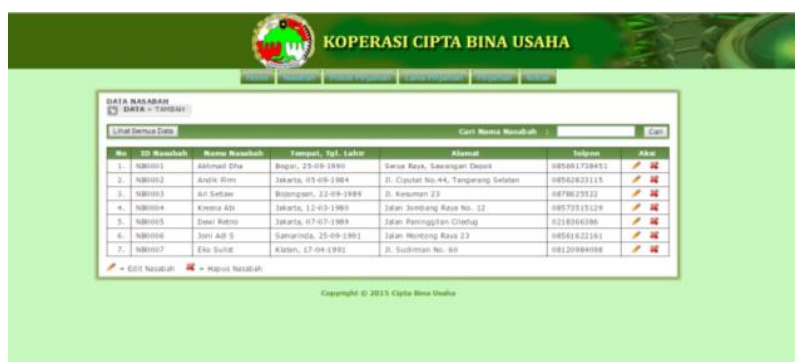

Gambar 6.

Tampilan Halaman Data Nasabah

Berikut ini adalah tampilan data pokok pinjaman gambar 7, dimana administrator dapat melihat, mengedit, dan menghapus data pokok pinjaman.

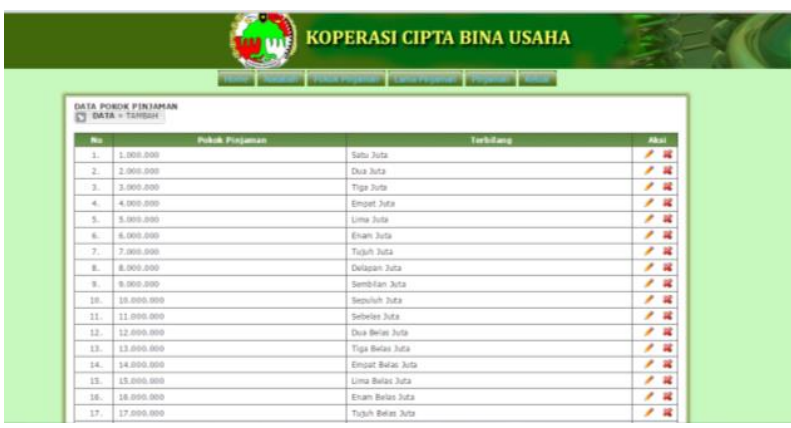

Gambar 7.

Tampilan Halaman Data Pokok Pinjaman

Pada gambar 8 merupakan tampilan data pinjaman yang berisi informasi mengenai detail nama, tanggal pinjam, pokok pinjaman, bunga, lama pinjaman, biaya angsuran dan jatuh tempo nasabah,

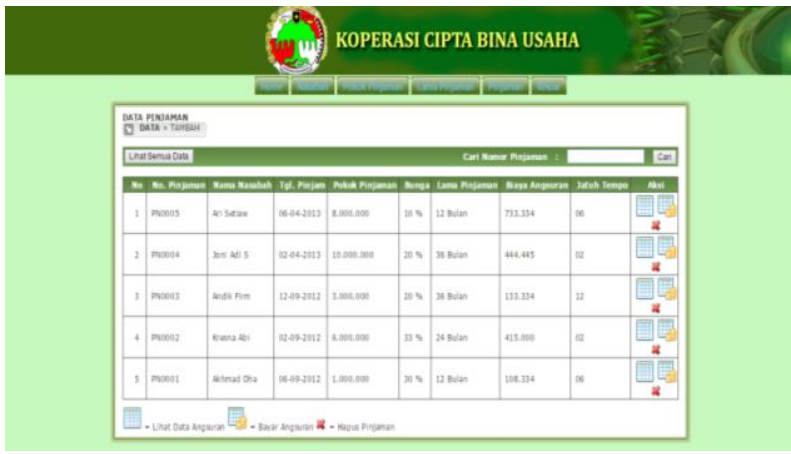

Gambar 8.

Tampilan Halaman Data Pinjaman

\section{KESIMPULAN DAN SARAN}

Berdasarkan riset, analisa pembahasan dan perancangan sistem yang telah penulis lakukan, dapat disimpulkan bahwa sistem informasi peminjaman kredit nasabah yang dirancang dapat digunakan untuk menyelesaikan masalah pada Koperasi Cipta Bina yaitu pengolahan data, memudahkan kegiatan peminjaman seperti dapat membantu nasabah untuk mengetahui berapa besar pokok pinjaman, besarnya angsuran dan lama pinjaman yang haru dibayarakan. Adanya aplikasi sistem peminjaman berbasis website ini administrator akan mudah dalam memberikan data pinjaman kepada nasabah dan ketua koperasi. Tersedianya database pada sistem informasi pinjaman diharapkan dapat mempermudah pencarian data pinjaman.

\section{Saran-Saran}

Agar sistem informasi peminjaman berbasis website ini berjalan dengan baik dan bisa memaksimalkan proses peminjaman dana oleh nasabah kepada Cipta Bina Usaha, maka penulis memberikan beberapa saran yaitu diperlukan pelatihan kepada administrator/kasir sebelum mengoperasikan sistem peminjaman ini dan untuk pengembangan sistem peminjaman dimasa mendatang perlu pengembangan sistem notifikasi via sms atau email.

\section{PUSTAKA}

C. Tristianto, "Penggunaan Metode Waterfall untuk Pengembangan Sistem Monitoring dan Evaluasi Pembangunan Pedesaan". J. Teknol. Inf. ESIT, vol. 12, pp. 8-22, 2018, doi: 10.1093/nq/182.23.321-a.

Isa, Indra Griha Tofik \& Hartawan, George Pri. 2017. "Perancangan Aplikasi Koperasi Simpan Pinjam Berbasis Web”. Jurnal Ilmiah Ilmu Ekonomi (Jurnal Akuntansi, Pajak dan Manajemen), 5 (10). pp. 139-151.

Kadir, Abdul. 2014. "Pengenalan Sistem Informasi Edisi Revisi”. Yogyakarta: Penerbit Andi.

Lasminiasih, dkk. 2016. "Perancangan Sistem Informasi Kredit Mikro Mahasiswa Berbasis Web”. Jurnal Sistem Informasi (JSI), Vol. 8, No. 1 .

Madcoms. 2013. "Kupas Tuntas Adobe Dreamweaver CS6 Dengan Pemrograman PHP \& MYSQL". Yogyakarta: Andi Publisher.

Rosa \& Shalahuddin. 2013. "Rekayasa Perangkat Lunak”. Bandung: Informatika.

Santoso.Sugeng, Nur Azizah, Afrilia Astari. 2018. "Aplikasi Sistem Informasi Pengajuan Kredit berbasis Web Pada PD. BPR Kerta Raharja Cabang Balaraja”. Konferensi Nasional Sistem Informasi 2018.

Sutedjo Dharma Oetomo. 2006. "Perencanaan Dan Pembangunan Sistem Informasi”. Yogyakarta

Widodo, P \& Herlawati. 2011. "Menggunakan $U M L "$. Bandung: Informatika

Y. Bassil, "A Simulation Model for the Spiral Software Development Life Cycle," Int. J. Innov. Res. Comput. Commun. Eng., vol. 03, no. 05, pp. 3823-3830, 2015, doi: 10.15680/ijircce.2015.0305013. 
Y. Harsono, dkk. 2006 . "Ideologi Koperasi Menatap Masa Depan”. Yogyakata: Pustaka Widyatama. 